\title{
Tratamento das ulcerações traumáticas bucais causadas por aparelhos ortodônticos
}

\author{
Antonio Adilson Soares de Lima*, Ana Maria Trindade Grégio**, Orlando Tanaka***,

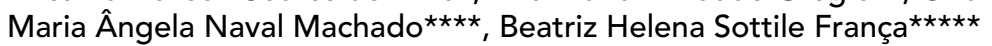

\begin{abstract}
Resumo
As lesões de aspecto ulcerado na mucosa bucal são um achado comum na clínica odontológica e geralmente são ocasionados por trauma mecânico devido a próteses mal adaptadas, aparelhos ortodônticos e dentes com coroas ou restaurações fraturadas. Contudo, os indivíduos nos quais a lesão persiste por mais de três semanas deverão ser submetidos à biopsia ou outros exames para excluir algumas lesões de caráter neoplásico ou outras condições, tais como as infecções crônicas e as doenças de caráter imunológico. Durante o tratamento ortodôntico, a dor e o desconforto da mucosa bucal podem acontecer como resultado do traumatismo mecânico dos aparelhos, ocasionado pela fricção aumentada entre o tecido da mucosa e a superfície dos braquetes. Atualmente, o ortodontista possui poucos recursos para prevenir ou aliviar esta irritação na mucosa. O objetivo deste artigo é orientar o ortodontista para o manejo mais adequado destas lesões visando o seu diagnóstico correto, o alívio dos sintomas que estas costumam provocar e o tratamento mais adequado para cada tipo de caso.
\end{abstract}

Palavras-chave: Úlcera. Traumatismo. Inflamação. Ortodontia. Antiinflamatório.

\section{INTRODUÇÃO}

A dor e o medo são sensações que acometem grande parte dos pacientes odontológicos, e até mesmo para certas especialidades, como no caso da Ortodontia, que convive diariamente com este tipo de queixa. As principais fontes de sintomatologia dolorosa, após a instalação de um aparelho ortodôntico, são a pressão no ligamento periodontal associado com a movimentação dentária e a presença de lesões ulceradas sobre a mucosa bucal, resultantes da friç̧ão aumentada dos braquetes com este tecido ${ }^{11}$.
As lesões ulceradas são comuns no dia-a-dia da clínica odontológica e sua prevalência é bastante variável, algo em torno de 4,6 a 30,7\% 3,6,10,15,17. De acordo com Kvam, Gjerdet e Bondevik ${ }^{12}$, cerca de $95 \%$ dos pacientes ortodônticos queixamse de dor durante o tratamento e, destes, 75,8\% das queixas estão associadas com a presença de ulcerações traumáticas na mucosa. Num outro estudo realizado por Kvam, Bondevik e Gjerdet ${ }^{13}$, cerca de $47 \%$ dos pacientes afirmaram que as úlceras causadas pelo aparelho fixo representavam a

* Professor Doutor em Estomatologia da PUCPR.

** Professora Doutora em Farmacologia da PUCPR.

*** Professor Doutor em Ortodontia da PUCPR.

**** Professora Doutora em Periodontia da PUCPR.

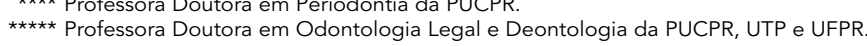


parte mais irritante do tratamento, seguidas pelo desconforto produzido pela ativação do aparelho que assumiu 38\% das queixas de dor. Lew ${ }^{14}$ afirma que as queixas de desconforto relacionadas ao uso de aparelhos ortodônticos variam de intensidade e de acordo com a região anatômica. Os resultados apontaram a língua e a mucosa jugal como as regiões anatômicas da boca mais envolvidas com a ocorrência destas lesões.

As ulcerações bucais são lesões de fácil diagnóstico e representam manifestações de doenças locais ou sistêmicas de etiologias infecciosas, imunológicas, neoplásica ou traumática. A história clínica do paciente facilmente determinará se as lesões são agudas ou crônicas, únicas ou múltiplas, primárias ou recorrentes - classificações que ajudarão bastante no diagnóstico diferencial ${ }^{4}$. As ulcerações aftosas recorrentes e aquelas de natureza traumática são mais freqüentes na boca.

Segundo $\mathrm{Lew}^{14}$, a valorização da aparência e a melhoria no estado psicossocial têm sido apontados como importantes fatores motivadores na decisão dos indivíduos em iniciar um tratamento ortodôntico. Desta forma, os profissionais precisam direcionar sua atenção além da mecanoterapia ortodôntica para outros aspectos subjetivos, tais como o desconforto e as atitudes dos pacientes durante o tratamento. O objetivo deste trabalho é descrever, de forma detalhada, as lesões que podem acontecer na mucosa bucal decorrentes do uso de aparelhos ortodônticos e as formas mais condizentes de tratamento.

\section{ALTERAÇÕES DA MUCOSA BUCAL ASSO- CIADAS AO TRATAMENTO ORTODÔNTICO}

A mucosa que reveste a boca é representada por uma camada externa de células epiteliais que é sustentada por tecido conjuntivo de constituição variável, a depender da região anatômica em que se encontra. Esta mucosa é uma barreira de proteção ao organismo, pois evita a penetração de qualquer agente externo que possa comprometer a sua saúde. Devido à boca executar diversas funções importantes, o seu forro tecidual vive em contínuo processo de renovação e também sofrendo diversas agressões, das mais diversas naturezas.

Um exemplo deste fato é o próprio tipo de alimentação do indivíduo, que tem o seu início na boca. Diariamente ingerimos uma grande quantidade de alimentos que possuem temperatura, consistência e $\mathrm{pH}$ variados. Outra possível fonte de agressão é o contato dos tecidos da mucosa com agentes físicos, tais como bordas de dentes com a coroa fraturada e/ou com restaurações defeituosas e ainda a superfície de aparelhos ortodônticos e próteses mal adaptados ${ }^{21}$. Dependendo da intensidade e do tempo deste estímulo nocivo poderemos observar várias alterações teciduais, principalmente no tecido epitelial. Segundo Brasileiro Filho², a ação da força mecânica sobre o organismo produz vários tipos de lesões, únicas ou múltiplas, genericamente chamadas de lesões traumáticas.

Atualmente, os ortodontistas dispõem de poucos recursos para prevenir ou aliviar as lesões da mucosa bucal. A irritação tecidual das extremidades, causadas por arcos de nivelamento, pode ser reduzida por meio do cuidadoso corte no extremo distal do arco e desgaste quando eles emergem da porção distal dos acessórios ortodônticos.

As primeiras alterações teciduais que ocorrem num tecido agredido mecanicamente podem ser observadas no epitélio. O que clinicamente se observa como áreas de coloração esbranquiçada podem ser traduzidas microscopicamente por áreas de hiperceratose reacional e sua presença é sinal de que algum agente traumático está atuando com baixa intensidade e já há algum tempo (Fig. 1, 2). A hiperceratose é um termo histopatológico que define um aumento na espessura da camada córnea e que ao sofrer umedecimento pela saliva torna-se visivelmente branca. Além do aumento da camada de ceratina, o epitélio pode ainda exibir área de edema intracelular, espongiose (edema intercelular), acantose (aumento da espessura da camada espinhosa) e hiperplasia (aumento no número das células). 


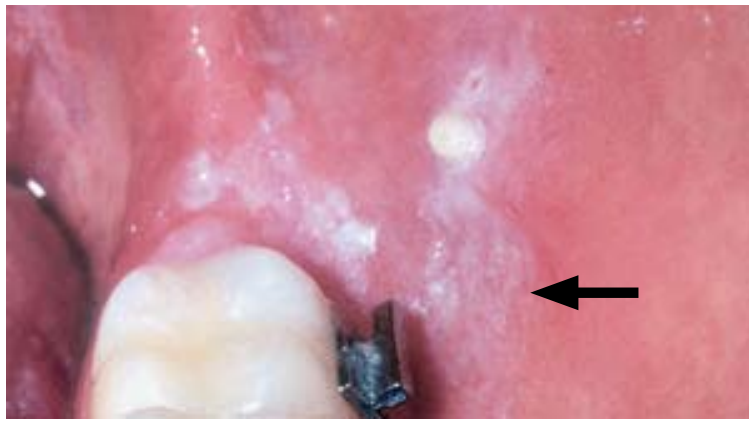

FIGURA 1 - Hiperceratose reacional na mucosa jugal provocada pelo atrito do tubo ortodôntico no dente 37 (seta).

A primeira medida que o profissional deverá executar ao se deparar com uma lesão de coloração branca é tentar verificar se esta desgarra facilmente após raspagem suave. Para isto, a lesão deverá ser raspada com auxílio de uma compressa de gaze, espátula metálica ou de madeira. Caso seja removida, provavelmente aquela lesão branca tratava-se de candidose na sua forma clínica pseudomembranosa, que é comum em crianças e idosos. Sendo assim, a saúde geral do paciente deverá ser investigada, pois a candidose bucal geralmente é assintomática e pode ser um indicador de um quadro de imunossupressão subjacente, e que alguns autores denominam de a "doença dos doentes". Fatores predisponentes localizados ou sistêmicos tais como: idade, gravidez, aparelhos ortodônticos e prótese mal higienizados, alta ingestão de carboidratos, deficiências nutricionais, diabetes mellitus, doença de Addison, hipotireoidismo, leucemias, AIDS, agranulocitose, hipossalivação, tabagismo, esteróides e antibióticos de amplo espectro por via oral deverão ser investigados ${ }^{16}$. $\mathrm{O}$ diagnóstico da candidose bucal é realizado baseado nos achados clínicos e seu tratamento deverá ser realizado por meio da prescrição de antifúngicos e, quando se tratar de pacientes ortodônticos, deve-se realizar uma higienização detalhada no aparelho. Isto pode ser obtido por meio da adequada escovação do aparelho com dentrifícios e sua imersão por aproximadamente 1 hora num copo contendo uma solução de água com 6 a 8 gotas de hipoclorito de sódio.

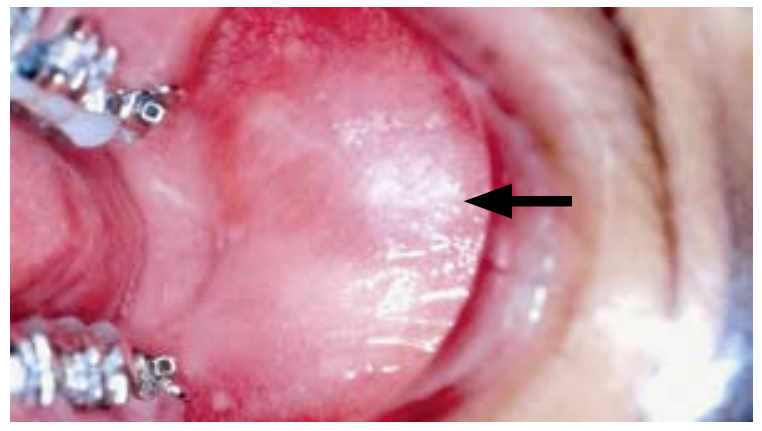

FIGURA 2 - Hiperceratose reacional na mucosa jugal provocada por traumatismo ortodôntico (seta).

Em se tratando de uma lesão branca resistente à raspagem, a primeira conduta é tentar correlacionar a área da lesão com alguma possível fonte de traumatismo mecânico, tais como o contato da mucosa com as bandas ortodônticas, tubos, botões ou ainda com a superfície oclusal dos dentes. Caso o agente traumático seja identificado, este deverá ser eliminado. Não havendo nenhuma correlação com agentes traumáticos, a lesão branca necessitará ser removida e submetida a exame histopatológico.

As lesões de aspecto clínico ulcerado seriam classificadas como abrasões ou feridas abrasivas que se caracterizam pela perda de células epiteliais pela ação de fricção ou esmagamento por um instrumento ou aparelho mecânico. De acordo com Regezi e Sciubba ${ }^{19}$, as úlceras traumáticas agudas da mucosa bucal apresentam sinais e sintomas clínicos da inflamação aguda. Estas lesões encontram-se cobertas por um exsudato amareloesbranquiçado e circundadas por um halo avermelhado (Fig. 3). Associadas às lesões agudas, existem a dor e também sensibilidade de grau variável.

Segundo Razmus ${ }^{18}$, as ulcerações traumáticas acontecem com maior freqüência apresentando as seguintes características clínicas:

- Acometem principalmente a mucosa jugal, borda da língua, lábios, gengivas e os palatos duro e mole;

- O tempo de duração variando de poucos dias a várias semanas, com a língua apresentando o maior tempo de evolução; 


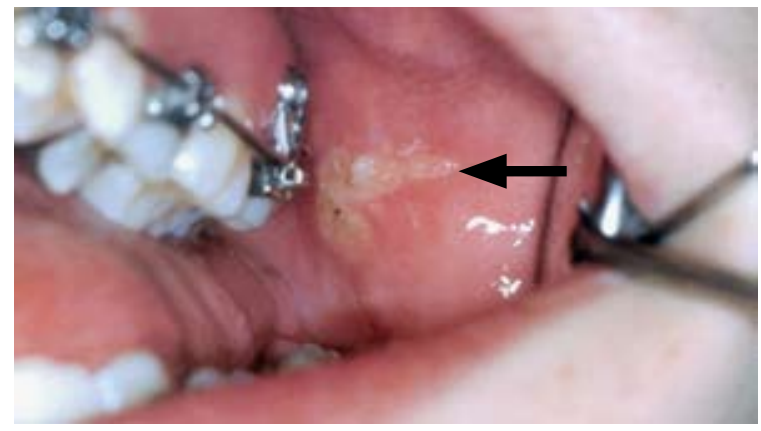

FIGURA 3 - Lesão ulcerada na mucosa jugal provocada por traumatismo ortodôntico (seta).

- O tamanho e a forma são variáveis e são geralmente lesões únicas. Se o agente traumático é removido não há recorrência;

- As margens da lesão são elevadas e avermelhadas;

- A base da úlcera é coberta por um material necrótico amarelo-brilhante que pode ser removido com uma compressa de gaze.

Indivíduos que apresentam lesões ulceradas recorrentes na boca deverão ser submetidos à criteriosa avaliação estomatológica para descartar outras doença de natureza sistêmica, tais como ${ }^{21}$ :

- Doenças Infecciosas - estomatite herpética, herpes zoster, herpangina, mononucleose infecciosa, infecção pelo vírus HIV, GUNA, tuberculose, sífilis e infecções fúngicas profundas;

- Doenças dermatológicas - líquen plano, pênfigo vulgar, penfigóide, eritema multiforme, dermatite herpetiforme, epidermólise bolhosa, estomatite ulcerativa crônica;

- Discrasias sangüíneas - anemia, leucemia, neutropenia;

- Doenças gastrointestinais - doença celíaca, doença de Crohn, colite ulcerativa;

- Drogas - agentes citotóxicos;

Da mesma forma, a fonte do trauma que é responsável pela produção da úlcera deverá ser encontrada e eliminada, caso contrário, a lesão evoluirá para a sua forma crônica (Fig. 4). O tempo de evolução da reparação de uma lesão ulcerada é variável. Fatores locais e sistêmicos relacionados

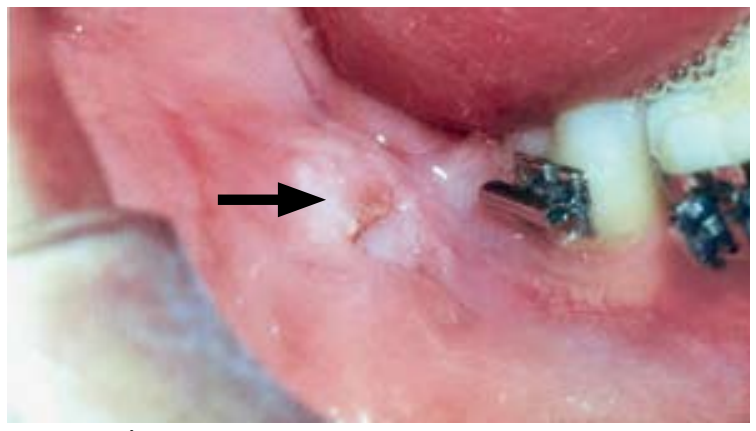

FIGURA 4 - Úlcera de aspecto crônico produzida pelo atrito com tubo ortodôntico no dente 47 (seta).

ao paciente poderão influenciar no processo de reparo destas lesões ${ }^{5}$.

Durante muito tempo, houve muita controvérsia sobre a correlação entre a transformação maligna causada por traumatismos crônicos de próteses dentárias ou dentes mal posicionados e/ou com arestas cortantes. Muitos autores procuram demonstrar evidências de que o trauma crônico em determinada região da boca seja o responsável pelo aparecimento de um carcinoma, enquanto outros atestam que este tipo de traumatismo não apresenta relação com a malignização de determinadas lesões. Até hoje, não se provou que o traumatismo crônico seja capaz de induzir mutações no DNA celular, fato indispensável para o desenvolvimento do câncer. $\mathrm{O}$ exposto procura demonstrar que quando essa associação entre o trauma crônico e o carcinoma bucal está presente, trata-se de coincidência, sendo que o risco real de transformação é realmente muito pequeno. Entretanto, é muito importante ressaltar que a eliminação sistemática de fatores traumáticos da mucosa bucal é uma das medidas importantes para prevenção de doenças bucais, pois é fundamental a manutenção de um quadro de higidez da mucosa, para que o diagnóstico precoce de mínimas alterações não seja mascarado por quadros crônicos. Ainda, a remoção do agente traumático, associada à eliminação do fumo e álcool, é uma medida segura e eficaz no controle do aparecimento de lesões bucais de diversos significados clínicos ${ }^{7}$. 
TRATAMENTO DAS ÚLCERAS BUCAIS DEVIDAS AO USO DE APARELHO ORTODÔNTICO

Os medicamentos empregados no controle da dor e do desconforto são rotineiramente administrados após procedimentos cirúrgicos, endodônticos e periodontais, mas é incomum serem conduzidos da mesma maneira após procedimentos ortodônticos associados com dor ${ }^{11}$. Vários são os medicamentos que podem ser utilizados para diminuir as lesões inflamatórias decorrentes do trauma causado pelo uso do aparelho ortodôntico. No que concerne a via de administração, preferem-se os medicamentos de uso tópico, ou seja, aqueles de ação local. Tal fato se deve em função de prevenir os efeitos colaterais e interações medicamentosas decorrentes do uso destes medicamentos. Pois, em muitos casos, os pacientes já recebem outras medicações, que não prescritas pelo cirurgiãodentista, sendo da obrigação deste preservar ao máximo a integridade fisiopatológica do paciente. Para tanto, a escolha da administração pela via tópica, acresce quanto ao custo do medicamento, além de reduzir seus efeitos colaterais e possíveis reações adversas.

Um dos principais medicamentos utilizados no controle e na redução das ulcerações da mucosa bucal são os antiinflamatórios, especialmente os antiinflamatórios esteróides também chamados de corticosteróides. Além destes medicamentos, também podem ser utilizados antissépticos, analgésicos e até mesmo compostos associados aos anestésicos locais, dependendo do grau de instalação do processo doloroso. Deve-se levar a termo a higienização bucal do paciente, para que não progrida no local um processo infeccioso.

\section{CORTICOSTERÓIDES}

Os corticosteróides são potentes antiinflamatórios, cujo princípio deriva dos hormônios esteróides, utilizando o colesterol como substrato, estes podem ainda ser chamados corticóides naturais. Existem análogos sintéticos, que conforme foram aprimorados reduziram-se significativamente os seus efeitos colaterais. Tais medicamentos são de uso restrito na Odontologia, exatamente pelos seus efeitos colaterais, mas a aplicação tópica e por período reduzido isenta o paciente destes efeitos.

Os corticosteróides promovem alívio dos sintomas inflamatórios, bem como redução da evolução clínica, por supressão da resposta inflamatória. A supressão da resposta inflamatória é dada em função do mecanismo de ação destes medicamentos, farmacodinamicamente, os corticosteróides impedem a formação da enzima fosfolipase A2, que será responsável por ativação do ácido araquidônico, este ainda se metabolizará em duas enzimas ativadoras do processo inflamatório - a ciclooxigenase e a lipooxigenase que, por sua vez, originam outros mediadores químicos (prostaglandinas, prostaciclinas, leucotrienos) que estão intrinsecamente ligados ao processo inflamatório.

O efeito dos corticosteróides torna-se maior, quanto maior for o período de contato com o tecido lesado. Logo é imprescindível que o paciente, ao aplicar este medicamento na mucosa lesada, o mantenha o maior tempo possível, e que sempre o faça após a escovação. Além disso, as preparações de corticosteróides utilizadas para aplicação oral devem estar na forma de Orabase, ou seja, uma formulação de carboximetilcelulose, polietileno e óleo mineral, que conferem maior adesão à mucosa e resistência à dissolução e deslocamento.

Principais medicamentos:

Omcilon-A (Bristol): $1 \mathrm{mg}-2$ a 3 vezes ao dia por 7 dias;

Triancinolona: $1 \mathrm{mg}-2$ a 3 vezes ao dia, 7 dias.

\section{PREPARAÇÕES FARMACÊUTICAS ALTERNA- TIVAS}

Várias são as alternativas às quais o ortodontista pode recorrer para o tratamento das lesões ulceradas, dentre elas, as preparações à base de extratos de plantas e produtos naturais. Extratos naturais, preparados para utilização na forma de colutórios, auxiliam no processo de reparo destas lesões e, em sua maioria, não possuem efeitos colaterais. 
A eficiência farmacológica da própolis sobre o processo inflamatório foi estudada por Grégio et al. ${ }^{9}$, que comprovaram que esta substância resinosa produzida pelas abelhas acelera o processo de reparo em lesões ulceradas de mucosa bucal. Logo, preparações farmacêuticas com extrato da própolis auxiliariam na cicatrização das lesões ulceradas causadas por trauma ortodôntico.

Preparações farmacêuticas contendo extrato de malva também possuem grande relevância na terapêutica odontológica e podem ser usados pelo ortodontista por um período de 7 dias, com 2 a 3 aplicações diárias ${ }^{20}$.

O uso de colutórios e enxagüatórios bucais além de auxiliar na higienização, também pode facilitar no reparo das lesões, uma vez que tais preparações contenham princípios ativos adequados. A formulação abaixo corrobora para o tratamento destas lesões.

- Prednisolona - 0,1\%

- Lidocaína - 2,0\%

- Água mentolada q.s.p - 60ml

Segundo Andrade ${ }^{1}$, esta solução poderá ser utilizada na forma de bochechos e ainda sob aplicação tópica na lesão.

Kluemper et al. ${ }^{11}$ demonstraram que a colocação de uma camada de cera misturada a um antiinflamatório produziu um maior efeito na redução dos níveis de dor dos pacientes usuários de aparelho ortodôntico fixo.

\section{TERRAMICINA®}

A Terramicina ${ }^{\circledR}$ (Pfizer) é o nome comercial de um antibiótico derivado das tetraciclinas. As tetraciclinas constituem um grupo de antibióticos bacteriostáticos de amplo espectro, que foram extensamente empregados no tratamento das infecções. As tetraciclinas também inibem proteinases destruidoras de tecidos, como colagenases e gelatinases, existentes em processos inflamatórios, provavelmente elas adicionariam à ação antibacteriana esse efeito estabilizador do colágeno, promovendo cicatrização das lesões ${ }^{8}$.

\section{TRATAMENTO DA CANDIDOSE}

A candidose é o tipo de infecção fúngica bucal mais comumente encontrada, principalmente em indivíduos usuários de prótese mal higienizadas ou portadores de algum quadro de imunossupressão. Em alguns casos sua recorrência se deve ao fato da posologia não ser respeitada, quanto ao tempo de tratamento. $\mathrm{O}$ mercado farmacêutico oferece uma gama de medicamentos que são eficazes no tratamento desta e cabe ao cirurgião-dentista a escolha do agente antifúngico de menor toxicidade sistêmica e aquele que melhor se adeque ao paciente em questão.

Para tanto, no ato da anamnese, cabe ao profissional certificar se o paciente não é portador de doença hepática ou renal. Vários medicamentos são descartados no caso de comprometimento hepático ou renal, tal como o clotrimazol. A nistatina é o fármaco de escolha, na forma de pastilhas ou aplicação tópica.

Em situações extremas onde há resistência fúngica, a alternativa terapêutica é a administração de itraconazol (dose de 200mg/dia), ou ainda, a anfotericina B (fármaco com considerada hepatotoxicidade) pela via intravenosa.

A clorhexidina é um agente antisséptico eficaz e por vezes útil no tratamento da candidose, utilizada na forma de enxagüatório bucal na concentração de 0,02 a 0,12\%, 2 a 3 vezes ao dia. A clorhexidina, por vezes, pode ser útil antes de procedimentos odontológicos, ou seja, como medida profilática, e os ortodontistas também deveriam adotar o uso desta, antes de seus procedimentos.

Caso não ocorra regressão da lesão em torno de 15 dias e ainda haja dúvidas quanto ao diagnóstico definitivo, então, recomenda-se a realização de uma biópsia da região envolvida. Se confirmado a presença de hifas no exame histopatológico devese recorrer a medicamentos mais eficazes, porém com custo mais elevado, indicando-se nesses casos os derivados azólicos (cetoconazol, fluconazol e itraconazol). 


\section{CONSIDERAÇÕES FINAIS}

O tratamento ortodôntico muitas vezes pode induzir o aparecimento de lesões ulceradas na mucosa bucal. O diagnóstico correto destas lesões é imprescindivel para se descartar outras doenças importantes de natureza não traumática.
Cabe ao ortodontista a eliminação do fator agressor causador da lesão e a aplicação de fármacos adequados, vislumbrando a reparação tecidual rápida e o alívio dos sintomas flogísticos.

\title{
Treatment of the mouth traumatic ulcers caused by orthodontic appliances
}

\begin{abstract}
Mouth ulcers are one of the most commom complaints in the dental clinic. They are, in general, caused for mechanic traumatism induced by non-fitted dentures, orthodontic appliances and fracturated crowns and fillings. Nevertheless, those lesions that have persisted for more than three weeks should be submitted to biopsy or other exams to exclude neoplasic, infectious or immunologic lesions. During the orthodontic treatment, pain and soreness of the oral mucosa can occur as the result of mechanic traumatism caused by increased friction between soft tissues and brackets. Nowadays, the professional owns few resources to prevention or relieve this irritation on the oral mucosa. The aim of this article is to guide the orthodontist to realize the correct diagnoses of the mouth ulcers, the relieve the symptoms and the exact treatment for each type of case.
\end{abstract}

Key words: Ulcer. Traumatism. Inflammation. Orthodontics. Anti-inflammatory.

\section{REFERÊNCIAS}

1. ANDRADE, E. D. Terapêutica medicamentosa em Odontologia. São Paulo: Artes Médicas, 1998.

2. BRASILEIRO FILHO, G. Patologia geral. 3. ed. Rio de Janeiro: Guanabara Koogan, 2004.

3. CAMPISI, G.; MARGIOTTA, V. Oral mucosal lesions and risk habits among men in an Italian study population. J Oral Pathol Med, Copenhagen, v. 30, no. 1, p. 22-28, Jan. 2001

4. COHEN, S. G.; SIROIS, D. A.; SOLLECITO, T. P. The diferentiation of intraoral ulcers. Hosp Pract, New York, v. 26, no. 5, p. 101-104, May 1991

5. COTRAN, R. S.; KUMAR, V.; ROBBINS, S. L. Patologia estrutural e funcional. 4. ed. Rio de Janeiro: Guanabara Koogan, 1991.

6. CRIVELLI, M. R.; DOMINGUEZ, F. V.; ADLER, I. L.; KESZLER, A. Frequency and distribution of oral lesions in elderly patients. Rev Asoc Odontol Argent, Buenos Aires, v. 78, n. 1, p. 55-58, jan./mar. 1990.

7. DIB, L. L.; KOWALSKI, L. P.; CURI, M. M. Lesões cancerizáveis da boca. In: KOWALSKI, L. P. et al. Manual de condutas diagnósticas e terapêuticas em Oncologia. 2. ed. São Paulo: Âmbito Editores, 2002. p. 406-410.

8. GOLUB, L. M.; LEE, H. M.; RYAN, M. E.; GIANNOBILE, W. V.; PAYNE, J.; SORSA, T. Tetracyclines inhibit connective tissue breakdown by multiple non-antimicrobial mechanisms. Adv Dent Res, Washington, D.C., v. 12, p. 12-26, Nov. 1998.

9. GRÉGIO, A. M. T.; BARBOSA, A. P.; RIBAS, M. O.; LIMA, A. A. S.; PEREIRA, A.C. P.; MARQUES, F. R. Efeito da propilos mellifera sobre o processo de reparo de lesões ulceradas na mucosa bucal de ratos - análise morfológica. In: SEMINÁRIO DE INICIACCÃO CIENTÍFICA, 10; MOSTRA DE PESQUISA DA PUCPR, 4., Curitiba, 2002. Caderno de Resumo. Curitiba, [s. n.], 2002. p. 90.

10. JAINKITTIVONG, A.; ANEKSUK, V.; LANGLAIS, R. P. Oral mucosal conditions in elderly dental patients. Oral Dis, Copenhagen, v. 8 , no. 4, p. 218-223, July 2002.
11. KLUEMPER, G. T.; HISER, D. G.; RAYENS, M. K.; JAY, M. J. Efficacy of a wax containing benzocaine in the relief of oral mucosal pain caused by orthodontic appliances. Am J Orthod Dentofacial Orthop, St. Louis, v. 122, no. 4, p. 359-365, Oct. 2002.

12. KVAM, E.; GJERDET, N. R.; BONDEVIK, O. Traumatic ulcers and pain during orthodontic treatment. Community Dent Oral Epidemiol, Copenhagen, v. 15, no. 2, p. 104-107, June 1987.

13. KVAM, E.; BONDEVIK, O.; GJERDET, N. R. Traumatic ulcers and pain in adults during orthodontic treatment. Community Dent Oral Epidemiol, Copenhagen, v. 17, no. 13, p. 154-157, June 1989.

14. LEW, K. K. Attitudes and perceptions of adults towards orthodontics treatment in an Asian community. Community Dent Oral Epidemiol, Copenhagen, v. 21, no. 2, p. 31-35, June 1993.

15. MARTINEZ DIAZ-CANEL, A. I.; GARCIA-POLA VALLEJO, M. J. Epidemiological study of oral mucosa pathology in patients of the Oviedo School of Stomatology. Med Oral, Madrid, v. 7, no. 1, p. 4-9, Jan./Feb. 2002

16. McINTYRE, G. T. Oral candidosis. Dental Update, London, v. 28 , p. 132-139, Apr. 2001

17. NAIR, R. G.; SAMARANAYAKE, L. P.; PHILIPSEN, H. P. et al. Prevalence of oral lesions in a selected Vietnamese population. Int Dent J, London, v. 46, no. 1, p. 48-51, Feb. 1996.

18. RAZMUS, T. F. Tongue ulcerated by trauma: report of a case. J Am Dent Assoc, Chicago, v. 123, no. 5, p. 82-86, May 1992.

19. REGEZI, J. A.; SCIUBBA, J. J. Patologia bucal: correlações clinicopatológicas. 3. ed. Guanabara Koogan: Rio de Janeiro, 2000

20. SALTE; J. L. O totum em fitoterapia: abordagem em fitobioterapia. Rio de Janeiro: Robe, 1996.

21. SCULLY, C.; PORTER, S. Orofacial disease: update for the dental clinical team: 2. Ulcers, erosions and others causes of sore mouth part I. Dent Update, London, v. 25, p. 478-484, 1998.

22. SCULLY, C.; SHOTTS, R. Mouth ulcers and others causes of orofacial soreness and pain. BMJ, London, v. 321, p. 162-165, July 2000.

Endereço para correspondência

Antonio Adilson Soares de Lima

Rua João Pontoni 120/1801 Cristo Rei

CEP: 80.050-490 - Curitiba/PR

E-mail: a.lima@pucpr.br 